\title{
Alteration of Connexins Gene Expression by Silibinin during Hepatic Warm Ischemia-Reperfusion Injury in a Rat Model
}

\author{
Amin Ghobadi ${ }^{1}$, Akram Mousavi $^{1}$, Hadis Musavi², Majid Malekzadeh Shafaroudi ${ }^{3}$ and Abbas Khonakdar-Tarsi ${ }^{1,4, *}$ iD \\ ${ }^{1}$ Department of Clinical Biochemistry and Genetics, Faculty of Medicine, Mazandaran University of Medical Sciences, Sari, Iran \\ 2 Department of Clinical Biochemistry, School of Medicine, Babol University of Medical Sciences, Babol, Iran \\ ${ }^{3}$ Anatomy and Cell Biology Department, Faculty of Medicine, Mazandaran University of Medical Sciences, Sari, Mazandaran, Iran \\ ${ }^{4}$ Molecular and Cell Biology Research Center, Faculty of Medicine, Mazandaran University of Medical Sciences, Sari, Iran
}

* Corresponding author: Abbas Khonakdar-Tarsi, Department of Clinical Biochemistry and Genetics, Faculty of Medicine, Mazandaran University of Medical Sciences, Sari, Iran. Tel: +981142241795; Email: khonakdarab@gmail.com

Received 2021 January 13; Revised 2021 February 01; Accepted 2021 March 18.

\begin{abstract}
Background: Ischemia-reperfusion injury (IRI) is an injurious phenomenon that is the primary determinant of liver dysfunction after surgery and transplantation. The present evidence demonstrated that connexin 43 ( $C x 43$ ), $C x 32$, and $C x 26$ are the essential gap junction proteins involved in the liver IRI.

Objectives: This study aimed to characterize the beneficial effects of silibinin on $C x 43, C x 32$, and $C x 26$ gene expression during warm hepatic ischemia-reperfusion (IR).

Methods: A total of 32 male Wistar rats weighing 250-300 g were randomly divided into four equal groups of eight animals in each group as follows: 1) control (laparotomy+normal saline), 2) laparotomy+silibinin (30 mg/kg) (SILI), 3) liver IR procedure+normal saline (IR), and 4) liver IR procedure+silibinin ( $30 \mathrm{mg} / \mathrm{kg}$ ) (IR+SILI). After $1 \mathrm{~h}$ of ischemia followed by $3 \mathrm{~h}$ of reperfusion, blood samples and tissue sections were gathered to assess the serum liver markers and evaluate the liver histological changes as well as gene expression, respectively.

Results: The obtained data proved no considerable differences between control and SILI groups in all experiments. Furthermore, the gene expression of $C \times 26, C \times 32$, and $C x 43$ was significantly induced in the IR group, compared to the control group. Silibinin markedly reduced $C x 26$ and $C x 32$ mRNA expression, whereas increased $C x 43$ mRNA expression. Moreover, serum alanine aminotransferase and aspartate aminotransferase levels were markedly elevated in the IR group $(\mathrm{P}<0.001)$, compared to the control group. However, in the IR+SILI group, silibinin could significantly decline these elevations, compared to the IR group. In addition, silibinin diminished hepatic tissue damages during IR.

Conclusion: Silibinin could attenuate liver injury through better cell-to-cell communication via lowering $C \times 32$ and $C \times 26$, as well as increasing Cx43 gene expression, respectively.
\end{abstract}

Keywords: Connexin, Gap junction, Ischemia-reperfusion, Silibinin

\section{Background}

Liver ischemia-reperfusion injury (IRI) is a pathophysiological process that occurs during partial or total obstruction of hepatic blood flow and oxygen depletion in the liver tissue and is sometimes necessary during surgical procedures. The renovation of blood flow to the ischemic liver tissue and reoxygenation triggers a molecular cascade that provokes further hepatocellular dysfunctions or even death (1). During reperfusion, many molecular mechanisms are involved in the pathogenesis of liver IRI and hepatocellular damage, including anaerobic metabolism, oxidative stress, mitochondrial dysfunction, intracellular $\mathrm{Ca}^{2+}$ overload, inflammatory response, neutrophil, and macrophage infiltration (2, 3). However, the actual molecular mechanisms of hepatic IRI have remained obscure.

Gap junctions (GJs) are specialized intercellular channels that directly connect the cytoplasmic compartments of the two adjacent cells and allow rapid intercellular exchange of ions and small molecules $<1000 \mathrm{Da}$, highlighting their role in the homeostasis of cells and tissues (4). A GJ channel is made up of two connexons or hemichannels from the two adjacent cells in a head-to-head organization. Each connexon contains six transmembrane protein monomers, which are called connexin $(C x)$. According to their molecular weight, $C x s$ are encoded by a conserved gene family with 21 different members in mammals, which are expressed in a cell-dependent pathway $(5,6)$. The $C \times 26, C \times 32$, and $C \times 43$, the building units of liver GJ, are expressed in the mature hepatocytes and Kupffer cells (5). A previous study has reported that $C \times 32$ plays an essential role in hepatic IRI by modulating hepatocyte apoptosis and damage (7). In acetaminophen-induced liver toxicity, $C x 43$ can lead to effective intercellular communication as part of the hepatic protective response (8). Moreover, during hepatic IRI and inflammation, an increase occurs in the hepatic $C_{x} 43$ expression leading to the converse changes in $C x 32$ and $C x 26$ expression (8-11).

\section{Objectives}

Silibinin, the principal active constituent found in 
silymarin, is extracted from the milk thistle plant (Silybum marianum). It has several therapeutic uses, including hepato-protective, anti-cancer, antioxidant, and anti-inflammation (12-14). In general, studies have shown that silibinin could suppress the tumor necrosis factor- $\alpha$ (TNF- $\alpha$ ) mRNA and protein expression. On the other hand, TNF- $\alpha$ represses the expression of $C_{x} 43$ in cardiac cells; therefore, silibinin can indirectly impede the repressive effect of TNF- $\alpha$ on the $C_{x} 43$ gene (15). Accordingly, this study aimed to investigate the silibinin effect on $C_{x} 43, C x 32$, and Cx26 gene expressions and liver tissue damages during IR in a rat model.

\section{Methods}

A total of 32 mature male Wistar rats weighing 250-300 g were obtained from the Research Center and Experimental Animal House of Mazandaran University of Medical Sciences, Sari, Iran. All of the experimental methods of Animal Breeding and Research of Mazandaran University of Medical Sciences were approved by the Ethical Committee of Mazandaran University of Medical Sciences, Sari, Iran. The animals were maintained and adapted in the laboratory under normal and standard conditions (12 hours of light/dark cycles and moisture of $55 \% \pm 5$ at $23 \pm 2^{\circ} \mathrm{C}$ ). After a one-week adaptation, the rats were randomly assigned into four groups each containing eight rats. These groups included: 1) Control (Vehicle) (animals were under laparotomy and received $0.9 \%$ sodium chloride [normal saline] intraperitoneally [IP] 30 min before laparotomy and immediately after the liver inserted into the abdominal cavity of the body), 2) Silibinin (SILI) (animals were under laparotomy and received 30 $\mathrm{mg} / \mathrm{kg}$ silibinin $30 \mathrm{~min}$ before laparotomy and immediately after the liver inserted into the abdominal cavity of the body), 3) Ischemiareperfusion (IR) (animals received normal saline 30 min before ischemia and immediately after reperfusion), and 4) IR+SILI (animals received silibinin $[30 \mathrm{mg} / \mathrm{kg}]$ before ischemia and immediately after reperfusion.

\subsection{Surgical procedure}

All animals were under fasting for $18 \mathrm{~h}$ before surgery; however, drinking water was unlimitedly accessible. They were then anesthetized by a mixed solution with an IP injection of ketamine (50 mg/kg) and xylazine $(8 \mathrm{mg} / \mathrm{kg}$ ). After creating a longitudinal incision on the ventral midline and bringing out the liver in IR and IR+SILI groups, the left branch of the triad port (including hepatic artery, portal vein, and biliary duct) was obstructed by a single metallic bulldog clamp for $60 \mathrm{~min}$ to create complete ischemia in the median and left lobes. Subsequently, the clamp was removed, and the liver was inserted into the abdominal cavity of the body to allow reperfusion for
3 h. The Vehicle and SILI groups were prepared similarly; however, vascular clamping was not applied. After the experimental periods, the animals were sacrificed, and the blood samples, as well as the liver tissue sections, were collected for further studies. Liver tissues were stored in RNAlater solution at $-70^{\circ} \mathrm{C}$. Furthermore, the serum separated from the blood samples was stored at $-20^{\circ} \mathrm{C}$.

\subsection{Silibinin administration}

Silibinin $(\sim 98 \%$ purity) was purchased in a lyophilized powder form with a dihydrogen succinate disodium salt formula (Legalon) manufactured by Rottapharm/Madaus (Cologne, Germany). It was injected twice (IP) in a total dosage of $60 \mathrm{mg} / \mathrm{kg} 1 \mathrm{~h}$ before laparotomy and immediately after the beginning of reperfusion each time $30 \mathrm{mg} / \mathrm{kg}(16,17)$.

\subsection{Biochemical analysis}

Serum levels of alanine aminotransferase (ALT) and aspartate aminotransferase (AST) enzymes were measured by a biochemical auto analyzer (BT-3000plus, Biotechnica, Italy) using the Pars Azmoon kit (Karaj, Iran).

\subsection{Total RNA extraction and real-time PCR}

According to the manufacturer's guidelines, an RNeasy plus mini kit (Qiagen, Germany) was used to extract the total RNA of all liver tissue samples. A UV spectrophotometer (Thermo Scientific, USA) was also utilized to evaluate RNA concentration at $260 \mathrm{~nm}$ and its purity at an absorbance ratio of $260 / 280$. In addition, RNA quality was confirmed by two sharpband detections for $18 \mathrm{~S}$ and $28 \mathrm{~S}$ ribosomal RNA by resolving electrophoresis in agarose gel stained with SYBR Green. According to the kit protocol, a concentration of $1 \mu \mathrm{g}$ of RNA per reaction was applied for cDNA synthesis (EURx, Poland). The reverse transcription Real-time PCR was performed according to the following steps: $50 \mathrm{ng}$ of cDNA ( $2 \mu \mathrm{l})$, $10 \mathrm{pM}$ of specific primers $(1 \mu \mathrm{l}$ of forward and reverse), $12.5 \mu$ l SYBR Green PCR Master Mix reagent (EURx, Poland), and DD water up to $25 \mu \mathrm{l}$ total volume. The PCR cycles were as follows: UNG pretreatment at $50^{\circ} \mathrm{C}$ for $2 \mathrm{~min}$, initial denaturation at $95^{\circ} \mathrm{C}$ for $12 \mathrm{~min}$, and 40 cycles $\left(95^{\circ} \mathrm{C}\right.$ for $15 \mathrm{sec}$ [denaturation]), $58^{\circ} \mathrm{C}$ for $30 \mathrm{sec}$ (annealing), and $72^{\circ} \mathrm{C}$ for $30 \mathrm{sec}$ (final extension). It is worth mentioning that the GAPDH gene was used for the normalization of the results, and the sequences of the primers are listed in Table 1.

\subsection{Histopathological study}

Liver tissue sections were fixed in $10 \%$ phosphate-buffered saline formalin, dehydrated with increasing ethanol grades, washed with xylene, and finally embedded into paraffin blocks for sectioning. The thin sections, about 3-5 $\mu \mathrm{m}$, were cut from paraffin-embedded samples with a microtome. 


\begin{tabular}{|c|c|c|c|}
\hline Genes & Forward Primer & Reverse Primer & Product Length \\
\hline$C x 26$ & 5'- CACTTCTGACCAACCCAGGAG -3' & 5'-GCTCTGTAGTGTGCCCCAAT -3' & 192 \\
\hline Cx32 & 5'- CAGACACGCCTGCATACATTC-3' & 5'- TAGAATGCCGATTCACGCCA-3' & 133 \\
\hline Cx43 & 5'- CATTGGGGGAAAGGCGTGAG-3' & 5'- GAAGCTTCCCCAAGGCACTC-3' & 204 \\
\hline GAPDH & 5'- AGTGCCAGCCTCGTCTCATA-3' & 5'- GATGGTGATGGGTTTCCCGT-3' & 248 \\
\hline
\end{tabular}

After deparaffinization with xylene, samples were stained with Hematoxylin and Eosin. Ultimately, all prepared slides were observed under an optical microscope (18).

\subsection{Statistical Analysis}

The data were analyzed in SPSS software (version 18), and REST-RG software was used to analyze the real-time PCR data. All results have been reported as the mean \pm standard error of the mean (mean \pm SEM). The mean difference between groups was also analyzed by one-way ANOVA, followed by Tukey's multiple comparison tests. A p-value less than 0.05 was considered statistically significant.

\section{Results}

\subsection{Biochemical results}

The comparison of liver tissue damage indices in the control and SILI groups did not show any significant changes $(\mathrm{P}>0.05)$. Furthermore, the IR caused a sharp increase in serum AST and ALT values $(\mathrm{P}<0.001)$. After the injection of silibinin, the levels of these indicators were significantly reduced, compared to the IR group $(\mathrm{P}<0.001)$ (Table 2$)$.

\subsection{Results of liver histopathology \\ 4.2.1. Vehicle group}

As shown in Figure 1, the structure of portal space, especially the hepatic artery branch, bile ducts, and the epithelium lining of them are intact and without any damage. In zones I and II of the classic lobules, hepatocytes display the circular and clear nuclei with one or two nucleoli and an intact cytoplasm space full of pink mitochondria. The intact sinusoidal space, Kupffer cells, and immune cells (neutrophils and small lymphocytes) are well identifiable. In zone I of the classic lobules, bile ducts with the simple cuboidal epithelium in the duct wall, and also the cross and longitudinal sections of the

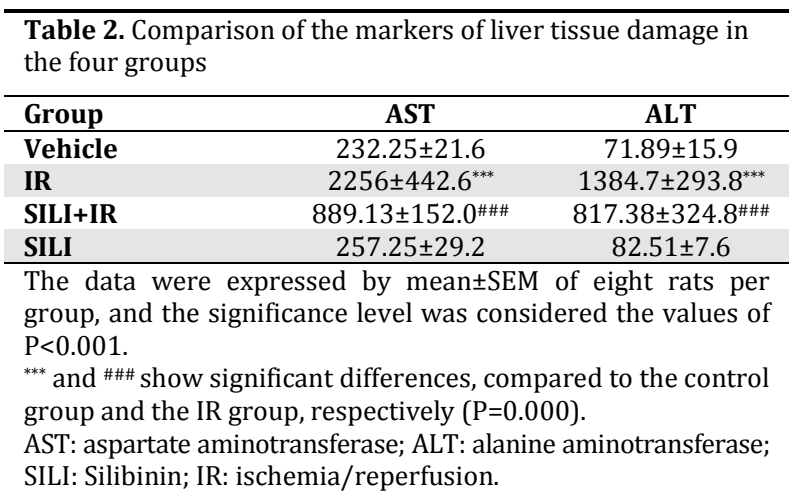

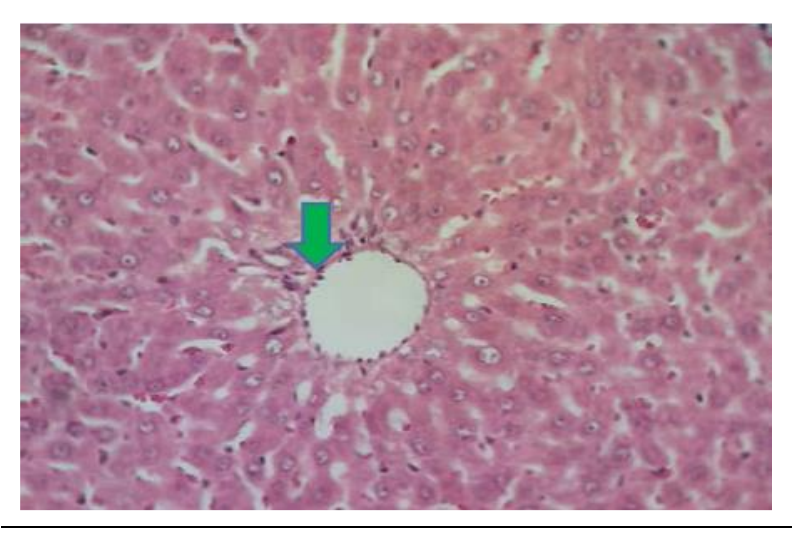

Figure 1. Histology of normal liver tissue sections with the normal saline injection into rat peritoneal (magnification $400 \mathrm{x}$ )

hepatic artery branch are visible at the margin of the classical lobule and inside the portal space. The hepatic artery endothelium with prominent nuclei in the lumen specifies the health of the artery.

\subsubsection{Silibinin group}

In Figure 2, the classic hepatic lobule appears healthy in different zones. The components of portal space, including branches of the blood vessel and their walls, as well as the bile ducts appear to be intact. Highly stainability of Remak trabecules with healthy nuclei, clear nucleoli, and minimal apoptotic vacuoles show the health of the liver tissue in the portal space and the surrounding classical zone I. Normal sinusoidal spaces are visible with intact endothelial lining and a large number of Kupffer cells. In general, the presence of silibinin did not cause any damage to the tissue structure of the rats' liver. In zones I, II, and III, the hepatocyte cords and sinusoidal spaces among them are completely healthy and undamaged.

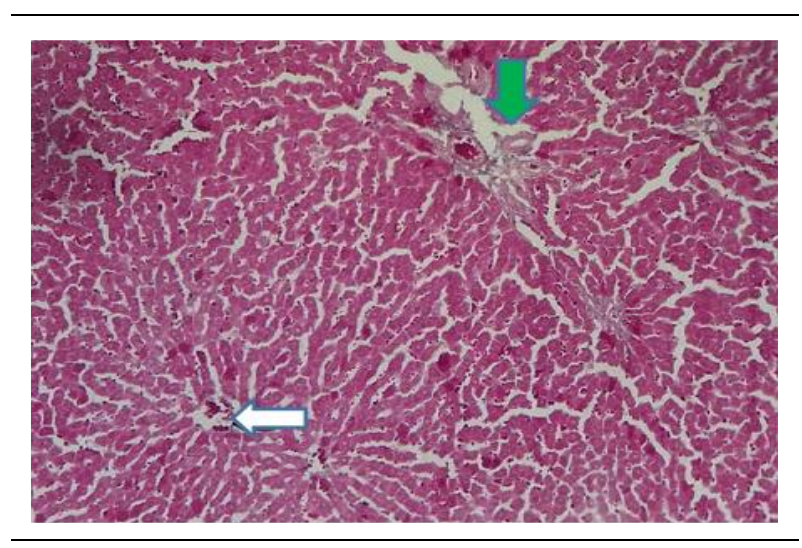

Figure 2. Evaluation of the liver sections treated with silibinin alone (magnification 100x) 


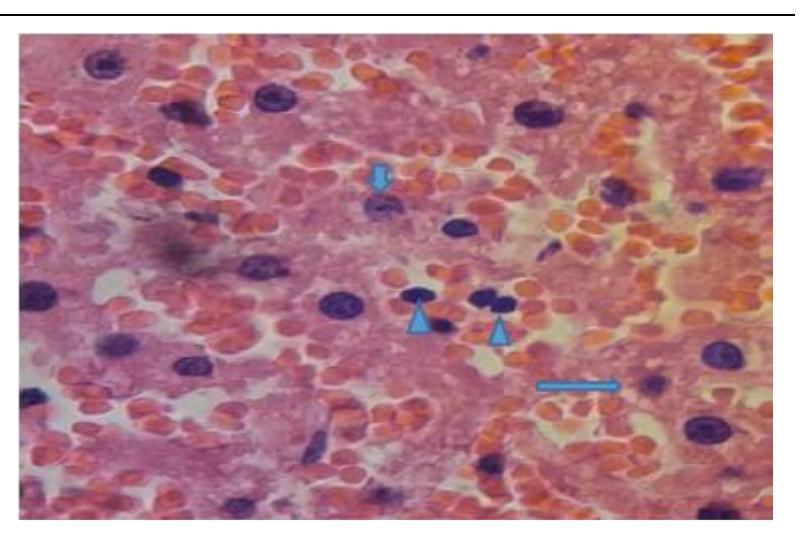

Figure 3. Examination of the liver sections with 1-hour ischemia (magnification 400x)

\subsubsection{Ischemia group}

The sinusoidal spaces in zone III are congested (hyperemia and atherosclerosis). In the sinusoidal wall, endothelial cells are severely damaged and desquamated; however, the central vein endothelium appears healthy. Some hepatocytes have become signet ring cells due to the extensive destruction of cytoplasmic organelles and the attachment of these apoptotic vacuoles. Hepatocyte Remak trabecules are visible with clear nuclei, as well as pale and vacuolated cytoplasm. Extensive infiltration of RBCs indicates sinusoidal congestion with extensive endothelial shedding overlying them (Figure 3).

\subsubsection{I/R+SILI group}

Figure 4D illustrates the silibinin protective effects against IR. Zones I and II of the hepatic lobules have a healthy structure. The healthy hepatocytes with many mitochondria have given a pink to red cytoplasm to the hepatic Remak trabecules. Circular nuclei with clear nucleoli, sinusoids with an intact endothelium, and a low density of red blood cells are observed in the sinusoidal space. The structure of the

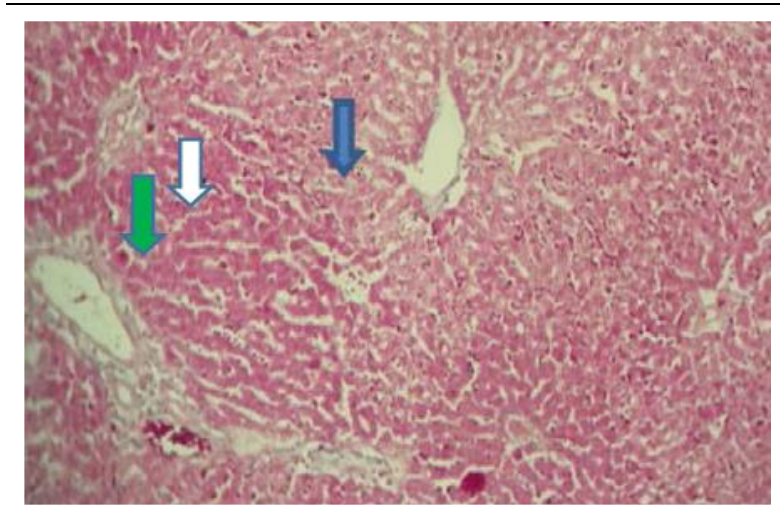

Figure 4. Evaluation of the liver sections with 1-hour ischemic treated with the protective effect of Silibinin (magnification 100x)

hepatic Remak trabecules and their interstitial sinusoids appear to be intact. However, the fading of zone III (blue arrow) surrounding the central vein shows some damage due to decreased mitochondrial density and an increased number of apoptotic vacuoles. The protective effect of silibinin in reducing the extent and severity of injury in these tissue sections is observed, compared to the IR group. Hepatic classic lobules in 100x magnification in zones I and II were marked with green and white arrows, respectively.

\subsection{Real-time PCR results}

Real-time PCR data analysis demonstrated no statistical differences between the control and SILI groups in terms of the mRNA levels of $C x 43, C x 32$, and $C \times 26$. Furthermore, the mRNA expression of $C x 32$, $C \times 26$, and $C x 43$ was significantly enhanced in the IR group, compared to the control group. In the IR+SILI group, silibinin reduced the $C \times 26$ and $C \times 32$ mRNA expression, compared to the IR group, whereas it had an inductive effect on the $C \times 43$ gene expression $(\mathrm{P}<0.001)$ (Figure 5).

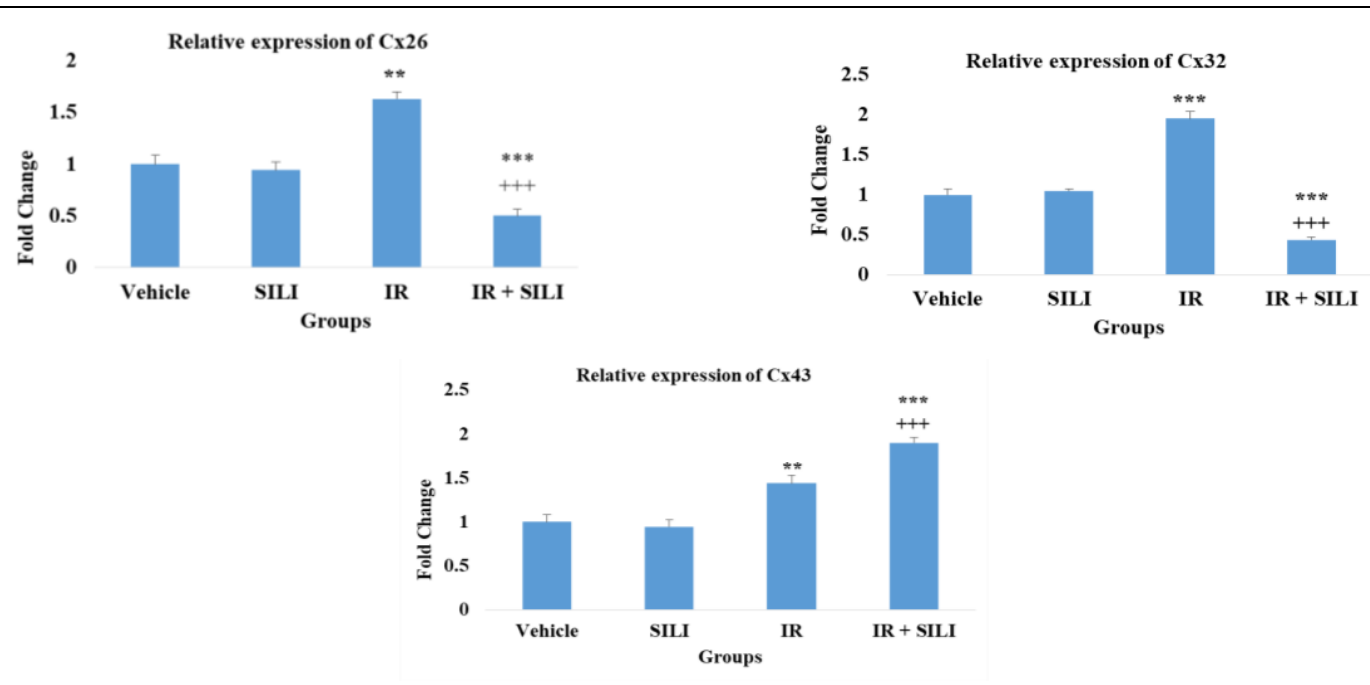

Figure 5. Relative $C \times 26, C \times 32$, and $C x 43$ gene expressions among the four studied groups. ${ }^{* *} \mathrm{P}<0.01$ and ${ }^{* * *} \mathrm{P}<0.001$, compared to the control group. ${ }^{++} \mathrm{P}<0.001$, compared to the IR group, SILI: Silibinin; IR: Ischemia/reperfusion; Cx: connexin 


\section{Discussion}

Research has shown that the kind of Cxs and the change in GJ channels play an important role in the IR damage in the liver tissue. It has been revealed that the transmission rate of IR damage signals is increased through GJs, which causes a chain of damages that lead to changes in cellular metabolism (7). The role of GJ inhibitors in reducing IR damage has been demonstrated in in vitro and in vivo models $(4,19,20)$. Recently, herbal medicines have been considered to reduce the effects of liver ischemia. The positive effects of silibinin on hepatocyte regeneration and IR damage have been proven (21); however, its effects on genes involved in gap junctions have not been studied so far. In the present study, the effect of silibinin was examined on the serum indicators of liver tissue injury, as well as $C x 43, C x 32$, and $C \times 26$ gene expression during warm hepatic IR. The IRI frequently occurs during transplantation and hepatic surgery; moreover, it promotes molecular reactions that enhance damage in the liver parenchyma (22-24). Several studies reported that GJ proteins are involved in liver IRI $(7,25)$. The GJs are the intercellular channels that mediate the passive diffusion of ions and small molecules, such as calcium, sodium, potassium, ATP, cyclic adenosine monophosphate, glutathione, and inositol triphosphate between the two adjacent cells. The diffusion of these substances via the GJs regulates a large number of physiological processes and tissue homeostasis. The $C x 26, C \times 32$, and $C x 43$ are the predominant GJ proteins detected in various liver cells, including hepatocytes, sinusoidal endothelial cells, and Kupffer cells (5).

Evidence demonstrated that $C x s$ are involved in liver IRI. Nakashima et al. demonstrated that the $C \times 26$ and Cx32 expression levels were down-regulated during liver tissue ischemia; however, they were increased during the early reperfusion phase of the rat model (9). In the same line, Patel et al. reported that increased expression of the $C \times 32$ gene was associated with liver injury, whereas its inhibition following hepatic reperfusion protected the liver against IRI $(7,25)$. In line with the previous studies, our results showed that $C \times 26, C \times 32$, and $C \times 43$ mRNA levels were up-regulated during the hepatic IR. It was also revealed that silibinin administration during IR could reduce endothelial damages, inflammation, and glycogen depletion; in addition, it preserved the mitochondrial membrane, which protected the liver against the IRI $(21,26,27)$. It was also determined in this study that silibinin could reduce the expression of $C \times 26$ and $C \times 32$; however, it could induce the expression of the $C x 43$ gene. Maes et al. pointed out that an increase in the $C x 43$ expression happened upon acetaminophen intoxication converse to the changes in $C \times 32$ and $C \times 26$ expression. They elucidated that increased expression of $C x 43$ might be due to hepatocyte de novo production in a classical response to stress and insult.

The above-mentioned study also revealed that Cx43-deficient animals were more susceptible to oxidative stress, inflammation, and death, compared to the wild-type animals. Therefore, $C_{x} 43$ may have a protective role in acetaminophen toxicity (8). Since the mechanism of liver damages in high-dose acetaminophen intoxication and ischemia-reperfusion is fundamentally similar, it can be concluded that the increased $C_{x} 43$-expression during IR may also play a protective role in this regard.

Hepatic IRI involves several cells in the liver organ, such as hepatocytes, sinusoidal endothelial cells, neutrophils, and Kupffer cells, which trigger multiple molecular pathways, including toll-like receptor (TLR) signaling activation and reactive oxygen species production $(28,29)$. The TLRs cause neuroinflammation by the triggering of $N F-\kappa B$ and pro-IL-1 $\beta$. Polyphenols, such as silibinin, lignans, flavonoids, phenolic acids, stilbenes, and phenolic alcohols can impede the increase of inflammatory cytokines by TLRs/NF- $\kappa \mathrm{B} / \mathrm{STAT}$ (signal transducer and activator of transcription) signaling path. Furthermore, some of the polyphenols can reduce neural apoptosis through the modulating of the TLRs/MyD88/NF- $\kappa$ B (30).

Ji-Hyeon Song et al. concluded that silibinin decreased the oxidative stress-related proteins and increased the glutathione and catalase expression. Furthermore, it could impede the TLR4-TAK1 signaling cascade and subsequent mediators of inflammation in RAW264.7 macrophage cells triggered by lipopolysaccharide (31). The antiinflammatory effects of silibinin are mostly due to inhibiting NF- $\kappa$ B nuclear translocation and activation that results in the inhibition of inflammatory cytokines, such as TNF- $\alpha$. TNF- $\alpha$ reduced the $C x 43$ expression; accordingly, silibinin could indirectly prevent the repressive effect of TNF- $\alpha$ on the $C \times 43$ gene and increased the expression of the gene (15).

Some histopathological and serum parameters were also investigated in this study to evaluate the impact of silibinin on liver tissue injury. Studies showed that serum levels of ALT and AST were raised during reperfusion with a maximal peak at $12 \mathrm{~h}$ after reperfusion (32). The effect of silibinin on ALT and AST levels are consistent with the results of the previous reports. Silibinin can decrease the damage and destruction of hepatocytes, as well as the level of these indices. Furthermore, it could prevent inflammatory cell infiltration, hepatocyte damage, and edema during IR (21). In this study, our histological results confirmed that silibinin declined neutrophil infiltration, endothelial damage, cellular degeneration, and vocalization in IR rats.

\section{Conclusion}

In this study, silibinin's liver-protective effects 
were proved by reducing the expression of specific GJ proteins $C x 26$ and $C x 32$, and the induction of $C x 43$ gene expression in the liver tissue under IR conditions. Furthermore, the histological study of the liver tissue suggested that silibinin dramatically reduced the serum levels of liver enzymes and liver damage. Our data documented the efficacy of silibinin in liver protection against IRI.

\section{Acknowledgments}

The authors express their gratitude to the head and staff of the Molecular and Cellular Biology Research Center of Mazandaran University of Medical Sciences, Sari, Iran, for their cooperation in conducting the experiments.

\section{Footnotes}

Authors' Contribution: Abbas Khonakdar-Tarsi designed the article. Amin Ghobadi and Akram Mousavi performed laboratory tests. Other authors participated in searching and writing the manuscript. All authors read the manuscript.

Conflict of Interests: The authors have no conflict of interest to declare.

Ethical Approval: The protocol of the experiments was approved by the Ethics Committee of Mazandaran University of Medical Sciences, Sari, Iran (Code: IR.MAZUMS.REC.1398.964).

Funding/Support: This study was supported by a grant from the Molecular and Cellular Biology Research Center of Mazandaran University of Medical Sciences, Sari, Iran (2606).

Financial Disclosure: None declared. Informed consent: Not applicable.

\section{References}

1. Cannistrà M, Ruggiero M, Zullo A, Gallelli G, Serafini S, Maria M, et al. Hepatic ischemia reperfusion injury: a systematic review of literature and the role of current drugs and biomarkers. Int J Surg. 2016;33(Suppl 1):S57-70. doi: 10.1016/j.ijsu.2016.05.050. [PubMed: 27255130].

2. Vardanian AJ, Busuttil RW, Kupiec-Weglinski JW. Molecular mediators of liver ischemia and reperfusion injury: a brief review. Mol Med. 2008;14(5-6):337-45. doi: 10.2119/200700134.Vardanian. [PubMed: 18292799].

3. Franchello A, Gilbo N, David E, Ricchiuti A, Romagnoli R, Cerutti E, et al. Ischemic preconditioning (IP) of the liver as a safe and protective technique against ischemia/reperfusion injury (IRI). Am J Transplant. 2009;9(7):1629-39. doi: 10.1111/j.1600-6143.2009.02680.x. [PubMed: 19519822].

4. Schulz R, Görge PM, Görbe A, Ferdinandy P, Lampe PD, Leybaert L. Connexin 43 is an emerging therapeutic target in ischemia/reperfusion injury, cardioprotection and neuroprotection. Pharmacol Ther. 2015;153:90-106. doi: 10.1016/j.pharmthera.2015.06.005. [PubMed: 26073311].

5. Maes M, Vinken M. Connexin-based signaling and drug-induced hepatotoxicity. J Clin Transl Res. 2017;3(Suppl 1):189-98. doi: 10.18053/jctres.03.2017S1.004. [PubMed: 28825041].

6. Abazari O, Divsalar A, Ghobadi R. Inhibitory effects of oxaliPlatin as a chemotherapeutic drug on the function and structure of bovine liver catalase. J Biomol Struct Dyn.
2020;38(2):609-15. doi: 10.1080/07391102.2019.1581088. [PubMed: 30767651].

7. Wu S, Yao W, Chen C, Chen H, Huang F, Liu Y, et al. Connexin 32 deficiency protects the liver against ischemia/reperfusion injury. Eur J Pharmacol. 2020;876:173056. doi: 10.1016/ j.ejphar.2020.173056. [PubMed: 32147436].

8. Maes M, McGill MR, da Silva TC, Abels C, Lebofsky M, de Araújo $\mathrm{CM}$, et al. Involvement of connexin43 in acetaminopheninduced liver injury. Biochim Biophys Acta. 2016;1862(6): 1111-21. doi: 10.1016/j.bbadis.2016.02.007. [PubMed: 26912412]

9. Nakashima Y, Kohno H, El-Assal ON, Dhar DK, Ono T, Yamano A, et al. Sequential changes of connexin32 and connexin26 in ischemia-reperfusion of the liver in rats. Hepatol Res. 2003;27(1):67-75. doi: 10.1016/s1386-6346(03)00188-8. [PubMed: 12957210].

10. Jeyaraman MM, Srisakuldee W, Nickel BE, Kardami E Connexin 43 phosphorylation and cytoprotection in the heart. Biochim Biophys Acta. 2012;1818(8):2009-13. doi: 10.1016/ j.bbamem.2011.06.023. [PubMed: 21763271].

11. Musavi H, Abazari O, Barartabar Z, Kalaki-Jouybari F, Hemmati-Dinarvand $\mathrm{M}$, Esmaeili $\mathrm{P}$, et al. The benefits of Vitamin $\mathrm{D}$ in the COVID-19 pandemic: biochemical and immunological mechanisms. Arch Physiol Biochem. 2020;8:1-9. doi: 10.1080/13813455.2020.1826530. [PubMed: 33030073].

12. Raina K, Kumar S, Dhar D, Agarwal R. Silibinin and colorectal cancer chemoprevention: a comprehensive review on mechanisms and efficacy. J Biomed Res. 2016;30(6):452-65. doi: 10.7555/JBR.30.20150111. [PubMed: 27476880].

13. Singh RP, Gu M, Agarwal R. Silibinin inhibits colorectal cancer growth by inhibiting tumor cell proliferation and angiogenesis. Cancer Res. 2008;68(6):2043-50. doi: 10.1158/00085472.CAN-07-6247. [PubMed: 18339887].

14. Shafaei Z, Abazari O, Divsalar A, Ghalandari B, Poursoleiman A, Saboury AA, et al. Effect of a synthesized amyl-glycine1, 10phenanthroline platinum nitrate on structure and stability of human blood carrier protein, albumin: spectroscopic and modeling approaches. J Fluoresc. 2017;27(5):1829-38. doi: 10.1007/s10895-017-2120-4. [PubMed: 28555407]

15. Kim S, Choi M, Lee H, Lee S, Kim S, Kim W, et al. Silibinin suppresses TNF- $\alpha$-induced MMP-9 expression in gastric cancer cells through inhibition of the MAPK pathway. Molecules. 2009;14(11):4300-11. doi: 10.3390/molecules14114300. [PubMed: 19924065].

16. Wu H, Tang $\mathrm{S}$, Huang $\mathrm{Z}$, Zhou $\mathrm{Q}$, Zhang $\mathrm{P}$, Chen $\mathrm{Z}$. Hepatoprotective effects and mechanisms of action of triterpenoids from lingzhi or reishi medicinal mushroom Ganoderma lucidum (Agaricomycetes) on $\alpha$-amanitin-induced liver injury in mice. Int J Med Mushrooms. 2016;18(9):841-50. doi: 10.1615/IntJMedMushrooms.v18.i9.80. [PubMed: 27910775].

17. Bosch-Barrera J, Corominas-Faja B, Cuyas E, Martin-Castillo B, Brunet J, Menendez JA. Silibinin administration improves hepatic failure due to extensive liver infiltration in a breast cancer patient. Anticancer Res. 2014;34(8):4323-7. [PubMed: 25075066].

18. Ghobadi M, Ghanaat K, Valizadeh-Dizgikan A, Gohari G, Roadi B, Khonakdar-Tarsi A. The effect of dexamethasone on expression of inducible nitric oxide synthase gene during liver warm ischemia-reperfusion in rat. Res Mol Med. 2015;3(3):17-22.

19. Wang N, De Vuyst E, Ponsaerts R, Boengler K, Palacios-Prado N, Wauman J, et al. Selective inhibition of $\mathrm{Cx} 43$ hemichannels by Gap19 and its impact on myocardial ischemia/reperfusion injury. Basic Res Cardiol. 2013;108(1):309. doi: 10.1007/ s00395-012-0309-x. [PubMed: 23184389].

20. Chen Y, Wang L, Zhang L, Chen B, Yang L, Li X, et al. Inhibition of connexin 43 hemichannels alleviates cerebral ischemia/ reperfusion injury via the TLR4 signaling pathway. Front Cell Neurosci. 2018;12:372. doi: 10.3389/fncel.2018.00372. [PubMed: 30386214].

21. Akbari-Kordkheyli V, Azizi S, Khonakdar-Tarsi A. Effects of silibinin on hepatic warm ischemia-reperfusion injury in the rat model. Iran J Basic Med Sci. 2019;22(7):789-96. doi: 10.22038/ijbms.2019.34967.8313. [PubMed: 32373301]

22. Lentsch AB, Kato A, Yoshidome H, McMasters KM, Edwards MJ. 
Inflammatory mechanisms and therapeutic strategies for warm hepatic ischemia/reperfusion injury. Hepatology. 2000;32(2):169-73. doi: 10.1053/jhep.2000.9323. [PubMed: 10915720].

23. Kupiec-Weglinski JW, Busuttil RW. Ischemia and reperfusion injury in liver transplantation. Transpl Proc. 2005;37(4):16536. doi: 10.1016/j.transproceed.2005.03.134.

24. Abazari O, Shafaei Z, Divsalar A, Eslami-Moghadam M, Ghalandari B, Saboury AA. Probing the biological evaluations of a new designed Pt (II) complex using spectroscopic and theoretical approaches: Human hemoglobin as a target. J Biomol Struct Dyns. 2016;34(5):1123-31. doi: 10.1080/07391102.2015.1071280. [PubMed: 26274094].

25. Patel SJ, Milwid JM, King KR, Bohr S, Iracheta-Vellve A, Li M, et al. Gap junction inhibition prevents drug-induced liver toxicity and fulminant hepatic failure. Nat Biotechnol. 2012;30(2):17983. doi: 10.1038/nbt.2089. [PubMed: 22252509].

26. Qajari NM, Shafaroudi MM, Gholami M, Khonakdar-Tarsi A. Silibinin treatment results in reducing OPA1\&MFN1 genes expression in a rat model hepatic ischemia-reperfusion. Mol Biol Rep. 2020;47(5):3271-80. doi: 10.1007/s11033-02005383-w. [PubMed: 32249375].

27. Zare Z, Dizaj TN, Lohrasbi A, Sheikhalishahi ZS, Asadi A, Zakeri M, et al. Silibinin inhibits TGF- $\beta$-induced MMP-2 and MMP-9 through Smad Signaling pathway in colorectal cancer HT-29 cells. Basic Clin Cancer Res. 2020;12(2):79-88.

28. Chen $\mathrm{W}$, Li D. Reactive oxygen species (ROS)-responsive nanomedicine for solving ischemia-reperfusion injury. Front Chem. 2020;8:732. doi: 10.3389/fchem.2020.00732. [PubMed: 32974285].

29. Dar WA, Sullivan E, Bynon JS, Eltzschig H, Ju C. Ischaemia reperfusion injury in liver transplantation: Cellular and molecular mechanisms. Liver Int. 2019;39(5):788-801. doi: 10.1111/liv.14091. [PubMed: 30843314].

30. Azam S, Jakaria M, Kim IS, Kim J, Haque M, Choi DK. Regulation of toll-like receptor (TLR) signaling pathway by polyphenols in the treatment of age-linked neurodegenerative diseases: focus on TLR4 signaling. Front Immunol. 2019;10:1000. doi: 10.3389/fimmu.2019.01000. [PubMed: 31134076].

31. Song JH, Kim KJ, Lee BY. Silibinin suppresses mediators of inflammation through the inhibition of TLR4-TAK1 pathway in LPS-induced RAW264. 7 cells. J Food Nutr Res. 2016;4:515-21. doi: 10.12691/jfnr-4-8-5.

32. Younis NN, Shaheen MA, Mahmoud MF. Silymarin preconditioning protected insulin resistant rats from liver ischemia-reperfusion injury: role of endogenous H2S. J Surg Res. 2016;204(2):398-409. doi: 10.1016/j.jss.2016.04.069. [PubMed: 27565076]. 